- Den 12. Jänner 1852 findet im landwirthschaftlichen Bezirksvereine Baden eine Generalversammlung statt.

- Die nächste Generalversammlung der k. k. LandwirthschafisGesellschaft in Wien ist vom Centralausschusse auf den 26. Jänner 1832, 9 Uhr Morgens, anberaumt worden.

- Das bereits mehrmals besprochene Project von dem Anlegen eines landwirthschaftlichen Institutes mit magyarischer Unterrichtssprache soll schon im kommenden Jahre in Ausführung gebracht werden.

- Die mathematisch-naturwissenschaftliche Classe der $k_{*}$ Akademie der Wissenschaften hält ihre Sitzungen in diesem Monate am 8. 15. und 22. ab. Am 29. findet eine Gesammtsitzung statt, an welcher nur wirkliche Mitglieder Theil nehmen.

\title{
Correspondenz.
}

- W i e n, im Jänner. - Mit wahrem Vergnügen lese ich in der letzten vorjährigen Nummer Ihres sehr geschätzten botanischen Wochenblattes, dass Sie dasselbe auch in diesem Jahre fortzusetzen den Entschluss gefasst haben, und dass Sie, trotz der vielen Schwierigkeiten, die İhnen von vielen Seiten her im Wege stehen, als wahrer Förderer der Botanik, kein Opfer scheuen werden, um Ihr sehr löbliches Beginnen fortzuführen. Dass unter diesen Schwierigkeilen auch die geringe Theilnahme osterreichischer Pflanzenfreunde figurirt, habe ich mil Bedauern entnommen, glaube thnen jedoch vollkommen, dass es so sei. Es ist eine eigenthümliche $\mathrm{Er}-$ zcheinung, dass man in Oesterreich in Bezug auf Naturforschung den eigenen Kräften so wenig traut. Ich könnte lhnen Männer aus allen Zweigen der Naturwissenschaft nennen, die bei den grünlichsten und tüchtigsten Kenninissen doch lieber zu auswärtigen Gelehrten ihre Zuflucht nehmen, statt auf eigenen Füssen ihre Errfahrungen und Kenninisse gemeinnützig zu machen. Wie viel von dem hier gesammelten Materiale wandert nicht nach Regensburg, Steitin oder Berlin, um uns von dorther als Neves und Interessantes wieder aufgetischt $\mathrm{zu}$ werden.... So lange diese Erscheinung andauern wird, dürfen Sie freilich nicht auf volle Theilnahme rechnen, denn eben so lange werden wir im eigenen Lande viel häufiger Lesern ausländischer Zeitschriften als des "Wiener bolanischen Wochenblattes" begegnen.

Hoffen wir jedoch, dass es bald anders werden möchte und dass in Wien wieder jene Zeiten einkehren möchten, wo der grosse J a c q u i n seine massgebenden, classischen Diagnosen dictirte; wo Host, Megerle,v. Mühlfeld, Ziegler, Treitschke und Trattin ik den Hafen bewachten, in welchen so manches verirrte Schifflein seine Zuflucht und die rechte Bahn wieder fanden.

Ist doch unser hochverehrter, hochgelehrter $F$ e n z l, an der Spitze eines Vereines, der schon seine Lebensfähigkeit bewährt hat, und zählt doch August Neilreich zu den thätigsten Mitgliedern desselben. Mittlerweile wollen Sie, hochgeehrter Herr Redac- 
teur, nicht ermüden, Ihr tüchlig begonnenes Work fortzuführen, und die Versicherung hinnehmen, dass viele, wahre Freunde der Pflanzenkunde Ihnen gewiss eben so dankbar sein werden, wenn śie es auch nicht ausdrücklich, wie hier geschieht, aussprechen sollten.

$\mathrm{Si}$ i a.

- F ï $\mathrm{nki} \mathrm{rche} \mathrm{n}$, in Ungarn in Jänner. -- Was meine Excursionen im Allgemeinen betrifft, so sind dieselben nicht nach Wunsch ausgefallen. Häufig wurde ich durch die schlechte Wilterung abgehalten, oder unterwegs vom Regen überfallen. Ein grösserer Ausflug, den ich während meinen Ferien nach Füred mit dem Cistercienserordens - Priester Professor M e j e r unternahm, gewährte mir bei einer achttägigen Reise nicht Einen schönen Tag, so dass ich gar nichts als ein Paar Exemplare Lepidium graminifolium erbeuten konnte.

Für die hiesige Flora neue Pflanzen fand mein Freund $\mathrm{Ne}$ n d tvi $\mathrm{ch}$. Wilh. eine Scrofularia unweit Domolos, welche ich für Scrof. Scopolii H p p. bestimmte, und ich fand nächst Fünfkirchen im Stadtwald die Potentilla micrantha $\mathrm{R}$ a $\mathrm{m}$ ond in zahlreichen Fxemplaren. Da ich dieselbe aber für $P$. fragariastrum $E \mathrm{~h} r \mathrm{~h}$. hielt, nahm ich nur drei Exemplare mit nach Hause, und erst nach einigen Wochen, wo die Pflanze schon abgeblüht hatte, gewahrte ich, dass es die wirkliche P. micrantha sei. Als neu für unsere Flora fand ich ferner noch: Inula hybrida Bm g., Polycnemum Heuffeli Lang, Alyssum minimum, Asplenium septentrionale Sw., Hieracium pratense, Gagea stenopetala, Thesium ramosum u. a. Eine Partie Corispermum nitidum W. K. könnte ich auch 'senden*), welche ich im verflossenen Jahre bei Pesth sammelte; es ist die echte, vom Kitaibelischer Standorte gesammelte Pflanze, und weicht von der bei Wien vorkommenden bedeutend $a b$.

Rudolf B a l e k.

- St if $\mathbf{Z} \mathbf{Z}$ e $t \mathbf{t l}$ in Nieder-Oesterreich im Jänner.

Gyalecta foveolaris (W a hl en b e r g) bisher bei Halie (W a ll roth), in Schlesien am Kitzelsberg ( $\mathrm{v}$. Flo tow), in der Schweiz an der Gemini, Gandritsch (S c h e r er), in der Provinz Como, um Triest und Idria ( $\mathrm{K}$ a b e $n$ h or $s t)$ aufgefunden; - fand ich heuer in einer Spalte eines Kalkfelsens am Bodenberg zu Heiligenkreuz.

Epipactis microphylla S w. Ich sammelte davon bei 200 Exemplare am Bodenberg bei Heiligenkreuz, und fand die sonderbare Erscheinung, dass die kriechende, faserige Wurzel eines jeden Exemplars zwischen zwei oder mehreren Kalksteinen eingezwängt war.

Diese Tage fand ich in unserer Stiftsbibliothek unter den Incunabeln ein Werk von $A$ I b e r t u $M$ a g n us ungefähr vom Jahre 1500, mit der Ueberschrift:

\section{Alberteus Magnas.}

Das Buch der versammlung, oder das Buch der hámligkayten Magni Albertivonden tugendender Kreiteretc.

;is Sie ist willkommen.

A n n. d. R ed. 